\title{
Immunotherapy with irradiated autologous leukemic cells in patients with B-CLL in early stages
}

\author{
IWONA HUS ${ }^{1}$, JERZY KAWIAK ${ }^{2}$, JACEK TABARKIEWICZ ${ }^{3}$, SEBASTIAN RADEJ ${ }^{3}$, \\ GRAZYNA HOSER ${ }^{2}$, AGNIESZKA BOJARSKA-JUNAK ${ }^{3}$, MICHAEL SCHMITT ${ }^{4}$, \\ KRZYSZTOF GIANNOPOULOS ${ }^{3}$, ANNA DMOSZYNSKA ${ }^{1}$ and JACEK ROLINSKI ${ }^{3}$ \\ ${ }^{1}$ Department of Hematooncology and Bone Marrow Transplantation, Medical University of Lublin, Lublin;
${ }^{2}$ Medical Centre of Postgraduate Education, Warsaw; ${ }^{3}$ Department of Clinical Immunology, Medical
University of Lublin, Lublin, Poland; ${ }^{4}$ Department of Internal Medicine III, University of Ulm, Germany
}

Received March 3, 2008; Accepted April 18, 2008

DOI: $10.3892 /$ or_00000027

\begin{abstract}
In this study $10^{7}$ peripheral blood mononuclear cells including on average $78.56 \% \mathrm{CD} 19^{+} / \mathrm{CD}^{+}$lymphocytes were irradiated, and then administered intradermally as an anti-cancer vaccine to seventeen patients with B-cell chronic lymphocytic leukemia (B-CLL) at early stages (twelve injections, four at a weekly interval followed by eight vaccines given every two weeks). In eight out of seventeen patients, in the first two injections, irradiated leukemic cells were mixed with Bacillus Calmette-Guerin (BCG) to improve the efficacy of therapy by additional induction of innate immunity. A hematological improvement (as defined by a $>25 \%$ reduction of leukocyte count) to autologous leukemic cell vaccines was observed in 5/17 patients, stabilisation of disease in 5/17 patients and in $7 / 17$ patients there was no response to immunotherapy. In seven patients significant increase of the lymphocyte doubling time was noted $(\mathrm{p}=0.02)$. There was no impact of BCG for immune responses or clinical outcome of vaccinated patients, but there was a significant increase of the absolute counts of $\mathrm{CD}^{+}$as well as of $\mathrm{CD}^{+} / \mathrm{CD}^{+}$and $\mathrm{CD}^{+} / \mathrm{CD}^{+} \mathrm{T}$ cells during the vaccination period. We observed a significant improvement of the phagocytic function of autologous dendritic cells generated from peripheral blood monocytes obtained from patients with B-CLL after the end of immunotherapy $(\mathrm{p}=0.006)$. An association between the clinical outcome and the percentage of leukemic cells positive for expression of ZAP-70 and CD38 was noted. In conclusion, our results demonstrated the feasibility and safety of autologous irradiated leukemic cell immunotherapy in patients with B-CLL. As we noted immunological, and to
\end{abstract}

Correspondence to: Dr Iwona Hus, Haematooncology and Bone Marrow Transplantation Department, Medical University of Lublin, Staszica 11, 20-081 Lublin, Poland

E-mail: iwohus@wp.pl

Key words: B-cell chronic lymphocytic leukemia, immunotherapy, irradiated leukemic cells some extent, clinical responses, this approach merits further investigation, including the use of adjuvants other than BCG.

\section{Introduction}

B-cell chronic lymphocytic leukemia (B-CLL) is the most common leukemia in western countries. The clinical course of B-CLL can be quite variable. Many patients survive many years with a good quality of life (QOL) without receiving any therapy, whereas others succumb rapidly despite aggressive treatment (1). It was established that treatment of early stage disease carries no benefit over a management of watching and waiting for progression (2). However, $~ 50 \%$ of patients with early stage disease develop a more advanced disease and will die from B-CLL and its complications. Therefore, it might be appropriate to reconsider the strategy of early therapy in B-CLL patients particularly those with high-risk prognostic factors. Most novel treatments, including purine analogues, monoclonal antibodies and combination immunochemotherapy, have significant risks for infectious complications $(3,4)$, which must be carefully weighted against the risks emerging from the underlying disease. Thus, cellular immunotherapies might constitute an advantageous therapeutical option, inhibiting disease progression and delaying the start of chemotherapy in early stage patients with relatively small tumor mass. The purpose of cancer vaccines is to induce host cell-mediated immune responses against autologous malignant cells as the modality to eliminate tumor. B-CLL cells express tumor antigens, such as Id protein, or more recently identified survivin (5), fibromodulin (6), and RHAMM (7), however the natural occurring clinical response to these LAAs is not sufficiently effective to eliminate the malignant clone. We questioned whether induction of apoptosis in irradiated leukemic cells would increase the antigenecity of malignant cells by enhanced presentation of tumor antigens, without requiring precise identification of antigenic targets. We further hypothesized, that antigens released from apoptotic leukemia cells, given intradermally as a vaccine could induce skin dendritic cell (DC) maturation and then their activation following migration to regional lymph nodes. In lymph nodes, DCs may present the processed 
leukemia antigens to $\mathrm{T}$ cells and activate them to cytotoxic $\mathrm{T}$ lymphocytes (CTLs) directed against B-CLL cells of the patient. These may contribute to breaking the tolerance of active $\mathrm{T}$ cells. In this phase I study, we assessed the feasibility, safety and immunogenicity of a vaccine consisting of irradiated apoptotic peripheral blood autologous leukemic cells used together with Bacillus Calmette-Guerin (BCG) as an adjuvant in 17 patients with B-CLL. BCG is an established treatment option for patients with bladder cancer $(8,9)$. It has also been used as an immunomodulating adjuvant, together with irradiated tumor cell vaccines in colon cancer patients (10). Since the early start of anti-cancer treatment would be especially beneficial for patients in early stages of B-CLL with poor prognostic factors, we analyzed the correlation between immune response as well as clinical outcome and prognostic factors, such as ZAP-70 and CD38 expression $(11,12)$.

\section{Materials and methods}

Patients. There were 17 patients enrolled in the study (eight women and nine men) with an age range from 38 to 70 years (mean 56.1 \pm 8.7 ). All patients were diagnosed with B-CLL in early stages (Rai 0-2) according to NCI (National Cancer Institute) criteria, and previously untreated. Patients were eligible for vaccine if they met the following criteria: a) ECOG (Eastern Cooperative Oncology Group) score <2, b) hepatic and renal functions not exceeding thrice the upper limit of normal, c) they had not received any immunosuppressive drugs and lacked autoimmune diseases, (d) life expectancy $>6$ months. Exclusion criteria included: a) severe cardiac, pulmonary, or other systemic disease associated with unacceptable anesthetic or operative risk, b) presence of acute infections requiring active treatment, c) prior history of other malignancies. The clinical protocol was approved by a local ethics committee (KE-0254/154/2002), and all patients gave their prior written consent for the therapy after detailed explanation of the procedure and possible problems in accordance with the Helsinki Declaration. The characteristics of the patients are summarized in Table I.

Preparation of vaccines. Whole blood was collected from the patients into heparinized tubes $(10 \mathrm{ml})$ before each vacination. Peripheral blood mononuclear cells (PBMCs) were isolated by density gradient centrifugation on Gradisol-L (Aqua Medica, Lodz, Poland) at $700 \mathrm{x}$ g for $20 \mathrm{~min}$. Leukemic lymphocytes constituted on average $\sim 78.6 \%$ of mononuclear cells (range 45.5-85.4\%). Next, mononuclear cells were washed twice in $0.9 \% \mathrm{NaCl}$, and $1 \times 10^{7}$ cells suspended in $1 \mathrm{ml}$ of $0.9 \% \mathrm{NaCl}$ were irradiated with $1000 \mathrm{~Gy}$ of $\gamma$-irradiation $\left({ }^{137} \mathrm{Cs}\right.$ ) using Gamma Cell 1000 Elite apparatus (Nordion International Inc., Canada) in order to induce apoptosis. The dose of $\gamma$-irradiation optimal for induction of apoptosis in leukemic B-cells was established in experiments in vitro (data not shown). Vaccines were administered to the patients immediately after preparation. An aliquot of cells was taken from each vaccine preparation for bacterial and fungal cultures to ensure sterility.

Treatment schedule. The vaccination course consisted of 12 injections of autologous irradiated leukemic cells adminis- tered according to the following schedule: first four injections given at one-week intervals and the remaining eight vaccines biweekly (Fig. 1). Patients were divided into two groups in order to evaluate the influence of BCG on the immune response as well as clinical outcome of the patients. In patients nos. 10-17, the first two doses of the vaccine contained, apart from leukemic cells, BCG suspension as an adjuvant $\left(10^{7}\right.$ cells, Bacillus Calmette-Guerin, type Mycobacterium bovis, subtype Brazilian Moreau obtained from Biomed (Lublin, Poland) with an intent to induce innate immune response. Vaccines were injected intradermally in close vicinity of the axillar and inguinal lymph nodes.

Evaluation of toxicity and clinical responses. Initial evaluation of the patients enrolled in the study included physical examination, complete blood count, lymphocyte subset analysis, and serum chemistry. These studies were repeated each time before vaccine administration and during subsequent followup examinations performed every three months for 12 months. Decrease of white blood cells (WBC) $>25 \%$ of initial value was considered as a hematological improvement. Patients were monitored for local and systemic toxicity according to the grading system of the National Cancer Institute (NCI-CTC).

Evaluation of immune responses (synopsis). The evaluation of immune responses included immunophenotyping of peripheral blood lymphocytes, proliferation assays of autologous $\mathrm{T}$ cells stimulated with leukemic apoptotic cells, ELISPOT assays to assess specific responses of autologous $\mathrm{T}$ cells to CD40L activated B-CLL cells and phagocytic function of monocyte-derived DCs. The schedule of immunological monitoring of immunotherapy is displayed in Fig. 1.

Immunophenotypic studies. The immunophenotype of peripheral blood lymphocytes was analyzed before the start of therapy, then before each vaccination, and two weeks after the end of treatment. The expression of the following cell surface antigens on the lymphocytes of each patient was determined: CD45/CD14, CD3/CD19, CD3/CD16/CD56, CD5/CD19, CD3/CD4, CD3/CD8 (antibodies used were purchased from Caltag Laboratories, CA, USA). The samples were acquired using a FACScalibur cytometer (Becton Dickinson, USA) and the data were analyzed using CellQuest software (Becton Dickinson, San Jose, CA, USA).

In all B-CLL patients participating in the study, expression of CD38 and ZAP-70 was determined at the moment of initial diagnosis by flow cytometry. Surface expression of CD38 on CD19+ B-cells was measured using anti-CD38 FITC monoclonal antibody (BD Pharmingen, San Diego, CA, USA). ZAP-70 protein kinase cytoplasmic expression in leukemic cells was assayed using the method described by Crespo et al (13) with some modifications (12). For this, mononuclear cells separated from peripheral blood by gradient centrifugation were stained with the anti-CD19PE and anti-CD5CyChrome monoclonal antibodies. Following membrane labeling, the cells were fixed in $0.5 \%$ paraformaldehyde and $70 \%$ ethanol $(1 \mathrm{~h})$, than permeabilized and incubated with the anti-ZAP-70 antibody, clone 2F3.2 mouse monoclonal $\mathrm{IgG}_{2 \mathrm{a}}$ (Biomol, Plymouth Meeting, PA, USA) for 


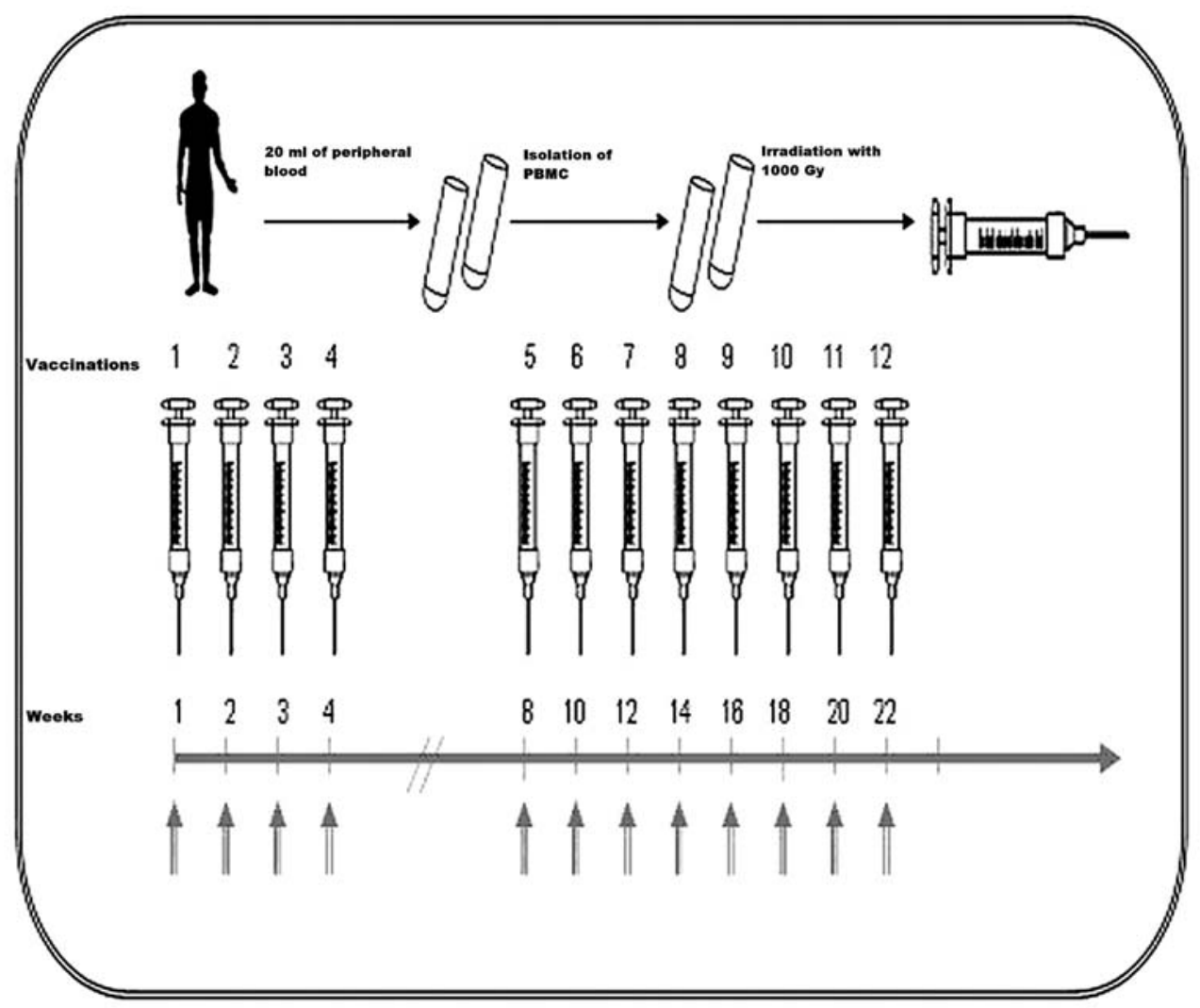

Figure 1. The schedule of vaccination and laboratory tests. Autologous PBMC were prepared from whole blood of the patients by density gradient centrifugation and irradiated with $1000 \mathrm{~Gy}$. Time points of vaccinations are indicated by syringes. Arrows indicate when differential blood count, serum chemistry and immunophenotyping of peripheral blood lymphocytes were performed. Before the start and after the end of immunotherapy (week 24) the phagocytic function of monocyte-derived DCs, T cell proliferation and specific CTLs were evaluated.

Table I. Clinical and laboratory characteristics of B-CLL patients treated with autologous irradiated leukemic cells.

\begin{tabular}{|c|c|c|c|c|c|c|c|c|c|c|}
\hline $\begin{array}{l}\text { Patient } \\
\#\end{array}$ & $\begin{array}{l}\text { Age } \\
\text { /sex }\end{array}$ & $\begin{array}{c}\text { Rai } \\
\text { stage }\end{array}$ & $\begin{array}{l}\text { Time from } \\
\text { diagnosis to } \\
\text { vaccinations } \\
\text { (months) }\end{array}$ & $\begin{array}{l}\text { LDT (months) } \\
\text { before/after } \\
\text { vaccinations }\end{array}$ & $\begin{array}{c}\text { WBC/ } \\
\text { lymphocytes } \\
\text { (G/l) before } \\
\text { vaccinations }\end{array}$ & $\begin{array}{l}\text { Lymph } \\
\text { node size } \\
(\mathrm{cm})\end{array}$ & $\begin{array}{c}\text { ZAP-70 } \\
(\%)\end{array}$ & $\begin{array}{c}\text { CD38 } \\
(\%)\end{array}$ & $\begin{array}{c}\beta_{2} \mathrm{MG}^{\mathrm{a}} \\
(\mathrm{mg} / \mathrm{l})\end{array}$ & $\begin{array}{c}\mathrm{LDH}^{\mathrm{a}} \\
(\mathrm{U} / \mathrm{l})\end{array}$ \\
\hline 1 & $53 / \mathrm{M}$ & 1 & 6 & $8 />18$ & $22.1 / 16.5$ & 1.0 & 9.78 & 6.69 & 1.34 & 420 \\
\hline 2 & $53 / \mathrm{F}$ & 0 & 48 & $36 />24$ & $19.6 / 15.6$ & $\mathrm{~N}$ & 2.58 & 4.06 & 1.48 & NT \\
\hline 3 & $55 / \mathrm{F}$ & 1 & 12 & $>12 />24$ & $18.7 / 13.3$ & 1.0 & 2.00 & 11.31 & 1.06 & NT \\
\hline 4 & $60 / \mathrm{F}$ & 1 & 12 & $>12 / 12$ & $31.3 / 25.8$ & 1.0 & 16.78 & 14.23 & $2.80^{\mathrm{b}}$ & 432 \\
\hline 5 & $56 / \mathrm{M}$ & 2 & 3 & $\mathrm{UN}>22$ & $38.3 / 30.1$ & $1.0-1.5$ & 11.47 & 8.23 & NT & 322 \\
\hline 6 & $66 / \mathrm{M}$ & 1 & 6 & $>24 />24$ & $13.8 / 8.7$ & $1.0-1.5$ & 12.90 & 7.64 & NT & NT \\
\hline 7 & $68 / \mathrm{M}$ & 1 & 48 & $>48 />1$ & $30.0 / 22.2$ & 1.0 & 10.39 & 1.16 & 1.60 & 433 \\
\hline 8 & $70 / \mathrm{M}$ & 0 & 6 & $3 / 10$ & $29.6 / 22.7$ & $\mathrm{~N}$ & $30.02^{b}$ & $42.10^{\mathrm{b}}$ & 1.60 & 422 \\
\hline 9 & $51 / \mathrm{M}$ & 1 & 3 & $3 / 7$ & $29.8 / 32.4$ & 1.5 & 4.52 & 10.52 & 1.50 & 311 \\
\hline 10 & $52 / \mathrm{F}$ & 1 & 18 & $12 />41$ & $43.5 / 32.8$ & 1.0 & 2.63 & 12.27 & NT & $511^{\mathrm{b}}$ \\
\hline 11 & $57 / \mathrm{F}$ & 2 & 18 & $18 />43$ & $48.2 / 40.5$ & 1.0 & 3.06 & 2.76 & NT & $648^{b}$ \\
\hline 12 & $63 / \mathrm{M}$ & 1 & 41 & $7 / 6$ & $31.0 / 25.9$ & $1.0-1.5$ & $44.34^{\mathrm{b}}$ & $29.26^{\mathrm{b}}$ & $2.30^{\mathrm{b}}$ & 296 \\
\hline 13 & $67 / \mathrm{M}$ & 1 & 5 & $>10 / 9$ & $39.3 / 27.9$ & $1.0-1.5$ & $27.26^{\mathrm{b}}$ & 10.21 & 1.60 & 433 \\
\hline 14 & $50 / \mathrm{F}$ & 2 & 18 & UN/16 & $26.0 / 20.9$ & $1.0-1.5$ & 2.26 & 2.50 & 1.70 & 277 \\
\hline 15 & $50 / \mathrm{M}$ & 1 & 2 & $14 / 21$ & $62.8 / 52.7$ & 1.0 & 12.70 & 2.64 & NT & 285 \\
\hline 16 & $38 / \mathrm{F}$ & 1 & 7 & UN/16 & $20.2 / 15.0$ & $1.0-1.5$ & 15.77 & $20.76^{b}$ & 1.83 & 261 \\
\hline 17 & $45 / F$ & 1 & 10 & $\mathrm{UN}>24$ & $23.5 / 18.0$ & $1.0-1.5$ & 13.36 & 18.56 & NT & NT \\
\hline
\end{tabular}

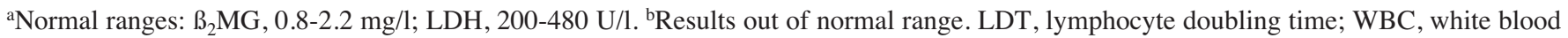
cells; NT, not tested; N, normal; UN, unknown. 

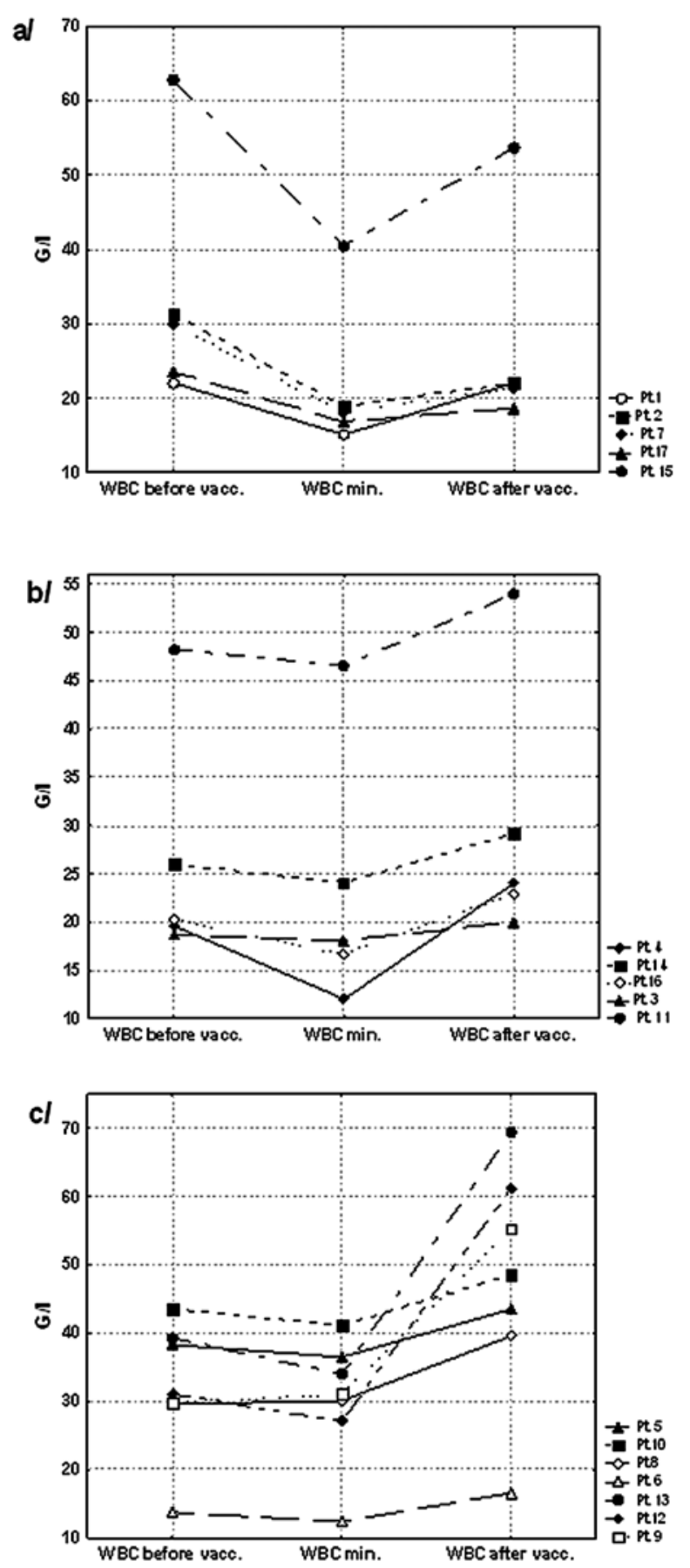

Figure 2. Mean WBC counts (G/l) before, during (the lowest value), and after the end of immunotherapy with autologous irradiated leukemic cells: (a) hematological improvement group; (b) stable disease group; (c) nonresponders group.

30 min. The antibody had been previously conjugated to fluorescing antibody using the Zenon Complex Formation Labeling Kit (Zenon $^{\mathrm{TM}}$ Alexa Fluor 488 Mouse $\mathrm{IgG}_{2 \mathrm{a}}$, Molecular Probes, Eugene, OR, USA) according to the manufacturer's instructions. The T lymphocytes, ZAP-70 ${ }^{+} /$ CD19-/CD5 ${ }^{+}$were used as an internal standard to determine the percentage of B-CLL cells positive for ZAP-70.

Proliferation assays. Proliferation assays to evaluate the proliferative response of $\mathrm{T}$ cells stimulated in vitro with autologous apoptotic leukemic cells was performed twice, before and two weeks after the end of immunotherapy using titrated thymidine incorporation assay. For this, autologous $\mathrm{CD}^{+}$cells were isolated from peripheral blood of B-CLL patients. MACS anti-CD3 microbeads and separation column (Miltenyi Biotec, Bergisch Gladbach, Germany) were used according to the manufacturer's instructions. Next, $\mathrm{CD}^{+}$cells were seeded in 96-well flat-bottom plates (Nunc, Denmark) $\left(5 \times 10^{4}\right.$ cells/well $)$. Isolated $\mathrm{CD}^{+}$cells were cultured with apoptotic leukemic cells (in 20:1 ratio) for 72 h. $\mathrm{CD}^{+}$cells cultured without addition of leukemic cells were used as the negative control. $\mathrm{CD}^{+}$cells stimulated with phorbol esters (PMA, Phorbol 12-myristate 13-acetate; Sigma-Aldrich, Germany) at a dose of $25 \mathrm{ng} / \mathrm{ml}$ PMA were used as positive control. ${ }^{3} \mathrm{H}$-thymidine $(1 \mu \mathrm{Ci} /$ well, Lacomed Ltd, Prague, Czech Republic) was added for the last $16 \mathrm{~h}$ of lymphocyte culture. Cells were harvested onto filter papers with a Skatron (Norway) harvesting apparatus. Thymidine incorporation was measured in a $\beta$-scintillation counter (Wallac 1409, PerkinElmer, Waltham, MA, USA) and the results from triplicate wells were expressed as mean counts per minute (cpm).

Phagocytosis assays. Phagocytic function of monocytederived DCs was evaluated twice, before and two weeks after the end of immunotherapy. Five-day cultures of adherent PBMCs were carried out in medium containing RPMI-1640 supplemented with $2 \%$ human albumin (ZLB Bioplasma AG, Bern, Switzerland), $100 \mathrm{IU} / \mathrm{ml}$ penicillin, $50 \mathrm{mg} / \mathrm{ml}$ streptomycin and $100 \mathrm{mg} / \mathrm{ml}$ neomycin. On days 1,3 and 5 of the culture $1000 \mathrm{IU} / \mathrm{ml}$ rhGM-CSF (Leukine, Berlex, USA) and $500 \mathrm{IU} / \mathrm{ml}$ rhIL-4 (Strathmann Biotec AG, Hannover, Germany) were added. At the end of the culture, generated immature DCs were re-suspended in RPMI-1640 (BioWhittaker, Belgium) and incubated with FITC-dextran (ICN, Germany) in concentration $1 \mathrm{mg} / \mathrm{ml}$ of medium at $37^{\circ} \mathrm{C}$ or at $4^{\circ} \mathrm{C}$ (control) for 4 and $24 \mathrm{~h}$. The incubations were stopped by adding cold PBS. The cells were washed twice with cold PBS and immediately analyzed for the presence of FITCdextran by flow cytometer and confocal microscopy (Carl Zeiss, Jena, Germany).

Assessment of specific $T$ cell responses to CD4OL stimulated $B$-CLL cells. B-CLL cells were incubated with CD40L in order to convert them to efficient APCs. Based upon data from the literature and our own previous results we chose a period of three days for the duration of CD40L stimulation $(14,15)$. PBMCs from B-CLL patients with early stage disease were thawed with a yield of $>95 \%$ viable cells and subsequently selected by CD19 magnetic beads through a MACS column (Miltenyi Biotec). More than $95 \%$ purity was reached in the $\mathrm{CD} 19^{+}$fraction. To obtain CD40L stimulated B-CLL cells (CD40L-B-CLL) CD19+ cells were cultured in standard RPMI medium (Biochrom AG, Berlin, Germany) supplemented with $0.5 \mu \mathrm{g} / \mathrm{ml} \mathrm{CD} 40 \mathrm{~L}$ soluble human (sCD40L, Strathmann). For culture-dependent negative control CD19 positive cells were cultured only in RPMI-1640 medium. Mixed lymphocyte cultures (MLC) were performed. CD3 ${ }^{+}$ lymphocytes were isolated from PBMCs using EasySep Isolation Kit (EasySep, Stem Cell Technologies, Canada) 


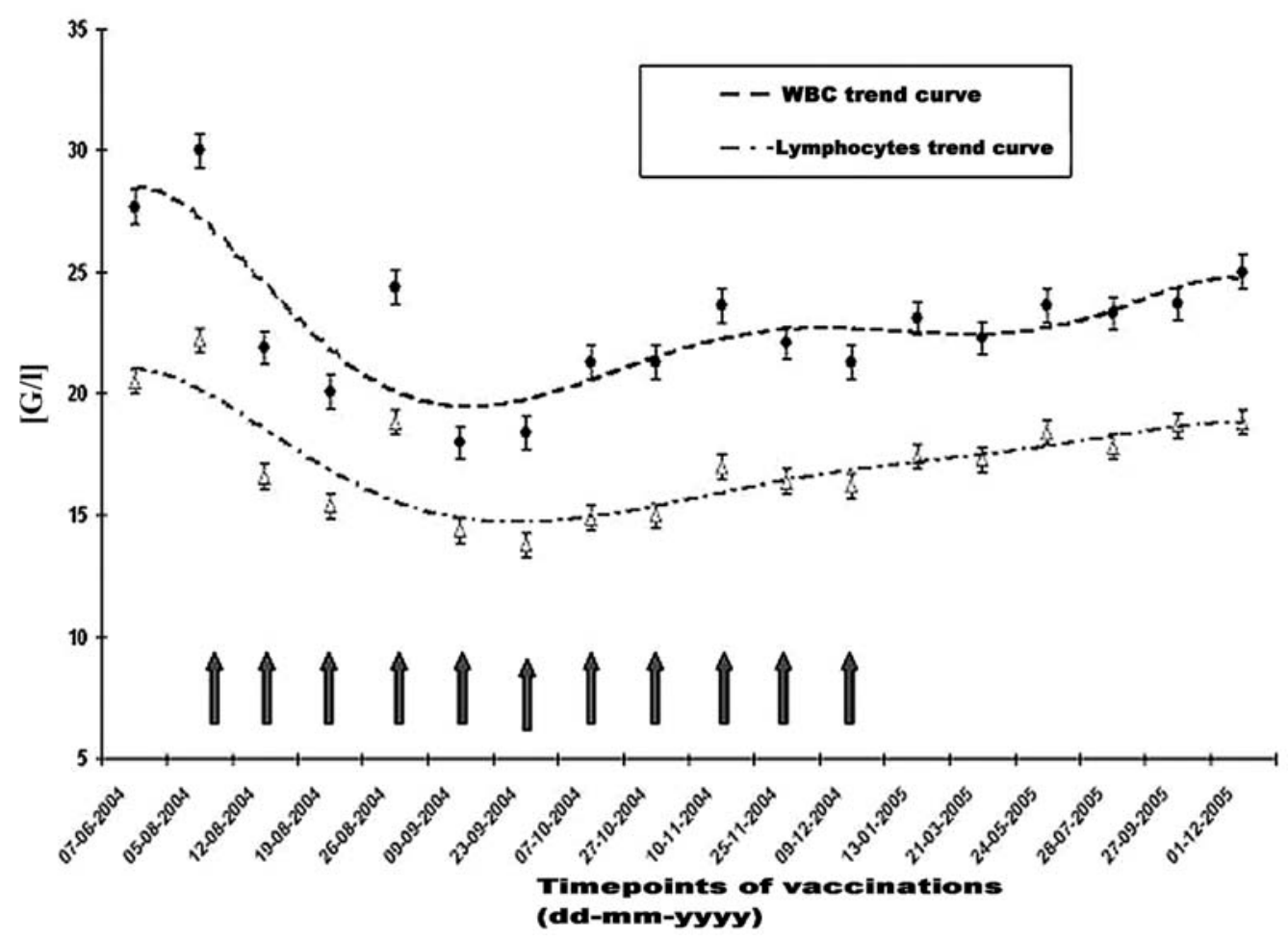

Figure 3. Leukocyte and lymphocyte trend curves of a patient with B-CLL treated with irradiated leukemic cell vaccines, from the time of initial diagnosis, during immunotherapy, and up to 12 months after the end of vaccinations (patient no. 7; hematological improvement group).

according to the manufacturer's instructions. CD3 ${ }^{+} \mathrm{T}$ cells were co-cultured with irradiated (30 Gy) CD40L-CLL cells in a 3:1 ratio, respectively. Culture medium (RPMI $+10 \% \mathrm{AB}$ serum) were supplemented with $10 \mathrm{U} / \mathrm{ml}$ IL-2 (human interleukin-2, Sigma-Aldrich, Munich, Germany) and $20 \mathrm{ng} / \mathrm{ml}$ IL-7 (recombinant, human interleukin-7, Strathmann) on day +1 . After 7 days of MLC the specific secretion of IFN- $\gamma$ was evaluated in ELISPOT assay against CLL and CD40LCLL targets, as described earlier (7).

Statistical analysis. Results were expressed as mean or median \pm standard deviation $(\mathrm{SD})$, standard error (SE) or ranges. In order to determine the statistical significance of the differences between groups the Mann-Whitney $U$ and ANOVA tests or the Wilcoxon matched-pairs test were used for unrelated or related variables, respectively. Statistical analyses were performed with Statistica 7.0 software program. P-values $<0.05$ were considered to be statistically significant.

\section{Results}

Clinical responses. All the patients completed the treatment schedule. Concerning response to the therapy, patients were divided into three groups: hematological improvement (HI) group; stable disease (SD) group and non-responders (NR) group. Hematological improvement was achieved in 5/17 patients (nos. 1, 4, 7, 15, 17). A stable disease was observed in $5 / 17$ patients (nos. $2,3,11,14,16)$. In $7 / 17$ patients there was no response to DC therapy (nos. 5, 6, 8, 9, 10, 12, 13). Fig. 2 shows the WBC counts of B-CLL patients treated with autologous irradiated leukemic cell vaccines during vaccinations with regard to response to therapy. In patients with hematological improvement, decrease of WBC and lymphocyte counts were rather transient, noted only during the vaccination period. An example trend curve of leukocytes and lymphocytes of a patient from the HI group is presented in Fig. 3. However, the lymphocyte doubling time (LDT) was significantly prolonged $(24.0 \pm 17.0$ months; median 21.0 vs $9.3 \pm 5.7$ months; median $8.0 ; \mathrm{p}=0.02)$ in seven patients (nos. 1, 3, 8, 9, 11, 15, 13), (Table I). After a median follow-up of 45.6 months from the start of vaccinations, in 10/17 patients the disease was still stable. Median time to the start of treatment in patients requiring chemotherapy was 20.1 months.

There were no differences in terms of clinical response between B-CLL patients receiving and not receiving BCG together with autologous irradiated leukemic cells. No correlation was found between the clinical response and either clinical or laboratory parameters measured before the start of the therapy (age, time from the initial diagnosis to the start of immunotherapy, WBC and lymphocyte counts, $\left.ß_{2} \mathrm{MG}\right)$.

Adverse events observed during immunotherapy were connected mainly with BCG injections. In all patients systemic symptoms such as fever (up to $38.5^{\circ} \mathrm{C}$ ), bone pains lasting for 2-3 days, and local reactions such as pain and ulcerations in the injection site resolving within 2-3 months were observed. In four patients vaccinated only with leukemic cells, flu-like symptoms resolving within one day were observed, together with a mild local reaction in the injection site resolving within 2-3 days. During the follow-up period (up to 45.6 months) no clinical or laboratory signs of autoimmune complications (Coombs and Waler-Rose tests, and antinuclear antibodies) 
a/

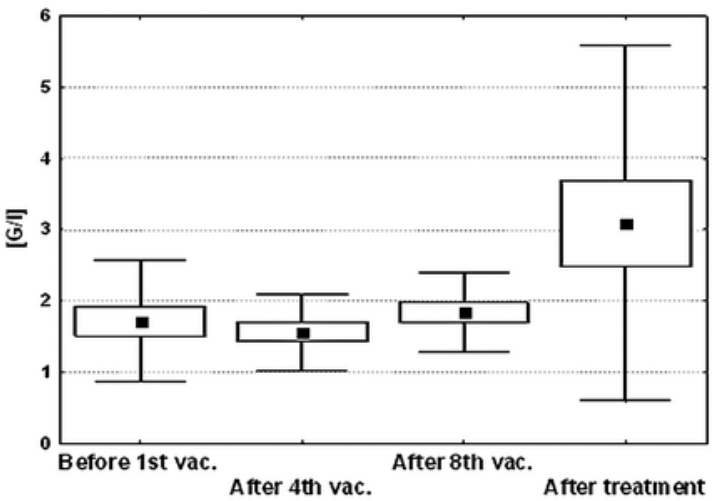

b/
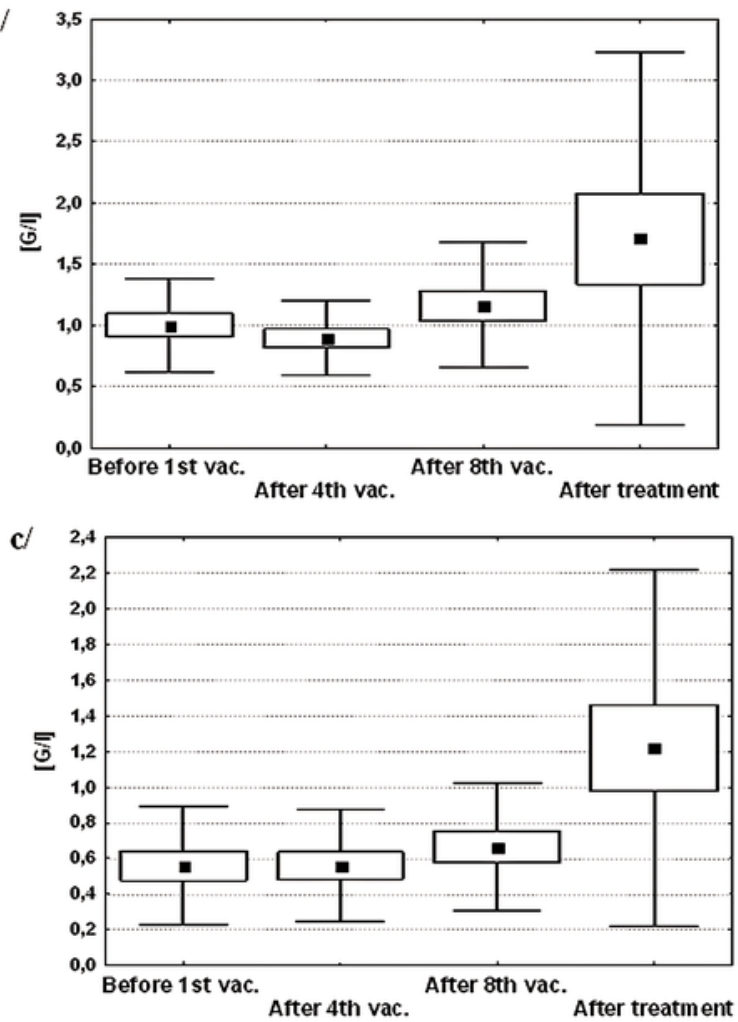

Figure 4. Absolute count of peripheral blood lymphocytes: i) $\mathrm{CD}^{+} \mathrm{T}$ cells; ii) $\mathrm{CD}^{+} / \mathrm{CD} 4^{+} \mathrm{T}$ cells; iii) $\mathrm{CD} 3^{+} / \mathrm{CD}^{+} \mathrm{T}$ cells in three groups of patients with B-CLL with regard to response to autologous irradiated leukemic cells vaccinations, measured before the therapy, and after the 4th, 8th and 12th vaccinations. (a) Hematological improvement group; (b) stable disease group; (c) non-responders group.

were observed. We did not note any significant changes of red blood cells, platelets or granulocytes counts during the vaccination period.

Immune response to vaccination. Flow cytometry analysis of lymphocyte subpopulations in PB of B-CLL patients treated with immunotherapy showed significant differences depending on the response to the treatment. Before the start of therapy the percentage of $\mathrm{CD}^{+}$and $\mathrm{CD}^{+} \mathrm{T}$ cells was higher in patients with subsequent response to the therapy or stable disease compared to the non-responders group $(6.06 \pm 2.59 \%$ vs $3.43 \pm 1.92 \%, \mathrm{p}=0.03 ; 13.74 \pm 32.31 \%$ vs $2.00 \pm 0.95 \%, \mathrm{p}=0.002)$. Moreover, during the whole immunotherapy period, percentage of $\mathrm{CD}^{+} \mathrm{T}$ cells was significantly higher in HI and SD groups compared to the NR group $(9.27 \pm 3.81 \%$ vs $7.00 \pm 4.24 \% ; \mathrm{p}=0.000001)$. The percentage of $\mathrm{CD}^{+}, \mathrm{CD}^{+}$and $\mathrm{NK}$ cells was significantly higher in the $\mathrm{HI}$ and SD groups compared to the NR group $(5.89 \pm 2.50 \%$ vs $3.89 \pm 3.12 \% ; \mathrm{p}=0.000001 ; 5.56 \pm 15.17 \%$ vs $2.13 \pm 1.04 \%$, $\mathrm{p}=0.00002 ; 7.07 \pm 15.99 \%$ vs $3.56 \pm 4.77 \% \mathrm{p}=0.001)$. After the last vaccinations $\mathrm{CD}^{+} / \mathrm{CD} 8^{+}$ratio was also significantly higher in the HI and SD groups compared to the NR group $(2.4 \pm 1.29$ vs $0.8 \pm 0.37, \mathrm{p}=0.045)$.

Evaluation of absolute counts of peripheral blood lymphocytes showed significant increase of $\mathrm{CD}^{+}(3.07 \pm 2.48 \mathrm{G} / 1$ vs $1.72 \pm 0.85 \mathrm{G} / 1, \mathrm{p}=0.006)$ as well as $\mathrm{CD}^{+} / \mathrm{CD}^{+}(1.71 \pm 1.51$ $\mathrm{G} / 1$ vs $1.00 \pm 0.38 \mathrm{G} / 1, \mathrm{p}=0.03)$ and $\mathrm{CD} 3^{+} / \mathrm{CD}^{+}+(1.22 \pm 0.99$ $\mathrm{G} / 1$ vs $0.56 \pm 0.33 \mathrm{G} / 1, \mathrm{p}=0.03$ ) $\mathrm{T}$ cells in the whole group of B-CLL patients vaccinated with autologous irradiated leukemic cells. Fig. 4 presents absolute counts of T cells and $\mathrm{T}$ cell subpopulations during vaccinations, with regard to the response to therapy.

In vitro $\mathrm{T}$ cell proliferation assay was performed in eight patients vaccinated with autologous irradiated leukemic cells and did not show any increase under the stimulation with autologous apoptotic/necrotic cells after immunotherapy, as compared to the initial values. Evaluation of specific $\mathrm{T}$ cell responses by ELISPOT method was performed before and after immunotherapy in two patients with clinical response. We did not find any significant activation of specific T cells secreting IFN- $\gamma$ after the contact with leukemic cells or leukemic cells activated by the incubation with CD40L (CD40-B-CLL).

Evaluation of phagocytic function of monocyte-derived DCs was performed in six patients (nos. 1, 2, 3, 5, 7, 8) before and after immunotherapy. Before the start of vaccinations, dextran-FITC uptake by immature DC was normal after $4 \mathrm{~h}$ of incubation and significantly lower after $24 \mathrm{~h}$ of incubation, as compared to healthy control subjects $(p=0.006)$. After vaccinations, dextran-FITC uptake was normal after $4 \mathrm{~h}$, as well as after $24 \mathrm{~h}$ of incubation (Fig. 5) indicating significant $(\mathrm{p}<0.037)$ improvement of phagocytic activity of monocytederived DCs due to immunotherapy.

Correlation between ZAP-70 and CD38 expression and clinical and immune response to autologous irradiated leukemic cell vaccines. ZAP-70 expression was positive in $3 / 17$ patients (nos. $8,12,13$ ), and in all of them there was no WBC and lymphocyte response to cellular immunotherapy. CD38 expression was also positive in three patients (nos. 8, $12,16)$; two of them were non-responders (nos. 8, 12), and in one patient (no. 16) stable disease was observed. Both patients with simultaneous expression of ZAP-70 and CD38 (nos. 8, 12) did not respond to immunotherapy. In contrast, all patients with clinical response were negative for ZAP-70 and CD38 expression. Additionally, we noted significant differences in $\mathrm{T}$ cells and $\mathrm{T}$ cell subpopulations between ZAP-70-positive and ZAP-70-negative as well as between CD38-positive and CD38-negative patients. Before the start of immunotherapy the percentages of $\mathrm{CD}^{+}, \mathrm{CD}^{+} / \mathrm{CD}^{+}{ }^{+} \mathrm{T}$ cells and $\mathrm{NK}$ cells were significantly higher in ZAP-70 negative comparing to ZAP-70 positive patients $(8.58 \pm 4.46 \%$ vs $6.71 \pm 3.09 \%$, $\mathrm{p}=0.02 ; 5.30 \pm 3.27 \%$ vs $3.71 \pm 1.82 \%, \mathrm{p}=0.01 ; 6.25 \pm 13.92$ vs $3.47 \pm 6, p=0.01)$. Similarly, the percentages of $\mathrm{CD}^{+}$, 


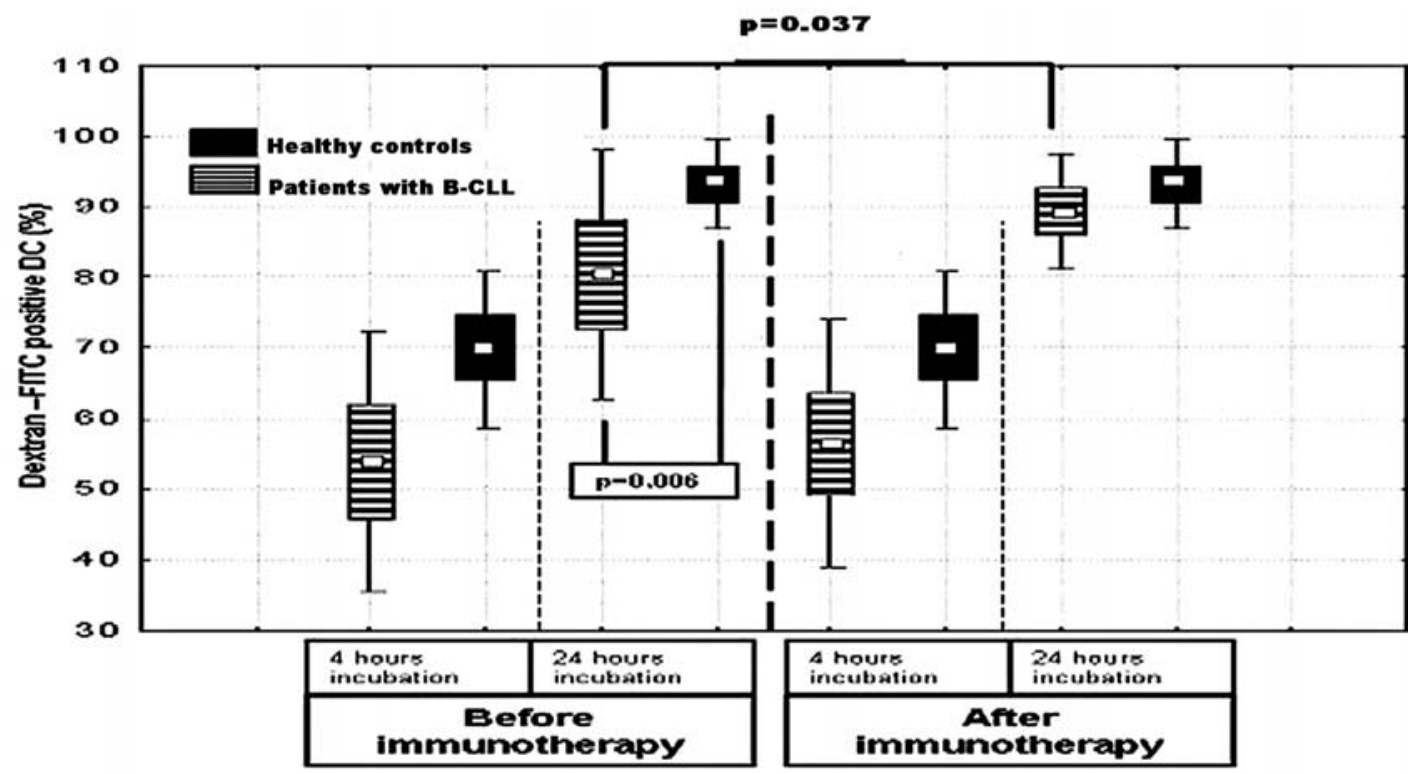

Figure 5. Comparison of phagocytic function of DCs generated from monocytes of patients with B-CLL before and after autologous irradiated leukemic cell vaccinations, evaluated by flow cytometry method.

$\mathrm{CD}^{+}{ }^{+} \mathrm{CD} 4{ }^{+}, \mathrm{CD}^{+}{ }^{+} \mathrm{CD} 8{ }^{+} \mathrm{T}$ cells, and $\mathrm{NK}$ cells, as well as $\mathrm{CD} 4{ }^{+} \mathrm{CD}^{+}$ratio were significantly higher in $\mathrm{CD} 38$ positive as compared to CD38 negative B-CLL patients $(8.46 \pm 4.23 \%$ vs $3.86 \pm 0.95, \mathrm{p}=0.00002 ; 5.15 \pm 3.10 \%$ vs $2.26 \pm 0.92 \%$, $\mathrm{p}=0.0004 ; 4.33 \pm 12.83 \%$ vs $1.77 \pm 0.70 \%, \mathrm{p}=0.05 ; 6.14 \pm 13.56 \%$ vs $0.86 \pm 0.16 \%, \mathrm{p}=0.01 ; 2.15 \pm 1.32$ vs $1.37 \pm 0.61, \mathrm{p}=0.05$ ).

\section{Discussion}

In the present work, we investigated clinical and immunological responses to autologous leukemic cells irradiated for induction of apoptosis and administered intradermally as an anti-cancer vaccine to 17 patients with B-CLL in early stages. A hematological improvement (defined as $>25 \%$ reduction in WBC count) to this vaccine was observed in $5 / 17$ patients, as well as stabilization of disease in 5/17 patients. In 7/17 patients no response to immunotherapy could be observed. An important clinical observation was significant increase of the lymphocyte doubling time (LDT) noted in 7/9 patients, suggesting that cellular immunotherapy might postpone progression and the start of chemotherapy. Interestingly, a prolongation of LDT was noted even in three patients with progressive disease. The dose of apoptotic/ necrotic cells in our study was similar to the dose used by other authors $(10,16,17)$ investigating the use of irradiated tumor cells as anti-cancer vaccines. Hitherto no reports have been published for higher cell numbers, which might result from difficulties connected with the acquisition of high numbers of cancer cells from patients with solid tumors. However, in patients with B-CLL a high number of malignant lymphocytes can be obtained from peripheral blood, which deserves elucidation in further trials. In 8 out of 17 patients, in the first two injections, irradiated leukemic cells were mixed with BCG with intent to improve the efficacy of therapy by additional induction of innate immunity. We did not find any significant benefit in terms of either immune or clinical response in patients treated with BCG. At the same time, the most inconvenient adverse events, such as painful ulcerations resolving within 2-3 months were connected with BCG injections. We used BCG as a non-specific immunotherapeutic adjuvant, based on previous studies in colon cancer and melanoma patients $(10,17)$. Vermorken et al reported a significant increase of recurrence-free survival together with a trend for a prolonged overall survival in patients with stage II and III colon cancer treated with adjuvant therapy with irradiated autologous tumor cells and BCG, as compared to the patients treated only with surgery (10). However, other studies by Hoover et al failed to confirm therapeutical advantages of BCG (18). These discrepancies might suggest a lesser significance of innate immunity in the anti-cancer response, but might also be connected to different types of tumors and of BCG, used in clinical studies. Mouse studies (19), as well as clinical observations in patients with bladder cancer confirmed the different therapeutic potential of BCG strains (20).

Flow cytometry of peripheral blood lymphocytes from B-CLL patients vaccinated in this study with apoptotic leukemic cells revealed that the percentage of $\mathrm{CD}^{+} \mathrm{T}$ cells, as well as $\mathrm{T}$ cell subpopulations $\left(\mathrm{CD}^{+}, \mathrm{CD}^{+}, \mathrm{NK}\right.$ cells) was significantly higher before and during immunotherapy in patients with clinical response or stable disease as compared to the patients with progressive disease. This observation indicates a significant association of immune competence of patients and their response to immunotherapy. Analysis of the novel prognostic factors in B-CLL patients treated with immunotherapy, showed an association between the clinical outcome and the percentage of leukemic cells positive for expression of ZAP-70 and CD38. Moreover, before vaccinations, in ZAP-70-positive patients $\mathrm{CD}^{+}$, as well as $\mathrm{CD}^{+} / \mathrm{CD}^{+}$ and $\mathrm{CD}^{+} / \mathrm{CD} 8^{+}$cell absolute counts were significantly higher as compared to ZAP-70-negative patients. Immune status seems to be the most important parameter for the results 
of the therapy, which is consistent with previous observations of Wierda et al (21) who found higher absolute counts of $\mathrm{T}$ cells at the time of CD40L gene therapy for B-CLL patients. Gitelson et al (22) analyzed immune responses to oxidized leukemic cell vaccines in B-CLL patients and suggested screening for CLL-reactive $\mathrm{T}$ cells to predict the response to immunotherapy. During vaccination, we observed a significant increase in the absolute count of $\mathrm{CD}^{+}$and $\mathrm{CD}^{+} \mathrm{T}$ cells, but not NK cells. These results confirm the induction mainly of specific immune response and to a lesser extent of the innate response. An increase in $\mathrm{T}$ cell numbers was noted in all patients, including non-responders, which is in agreement with the prolongation of lymphocyte doubling time observed also in patients with progressive disease. An increase in $\mathrm{T}$ cell numbers seems to be an advantageous effect of immunotherapy. Wierda et al (21) also observed a significant increase of $\mathrm{CD}^{+}$as well as $\mathrm{CD}^{+} / \mathrm{CD}^{+}$and $\mathrm{CD}^{+} / \mathrm{CD}^{+} \mathrm{T}$ cell absolute counts vaccinating B-CLL patients with autologous leukemic cells transduced with CD40L. Though an increase of T cell absolute count has been described $(23,24)$ in advanced stages of B-CLL, suggesting their role supporting tumor growth, studies by Shimoni et al (25) in a mouse model showed that the function of $\mathrm{T}$ cells is different, depending on the stage of B-CLL. In the early stages, $\mathrm{T}$ cells inhibit the proliferation of malignant B-cells, and in advanced stages enhancement of tumor growth is predominant. Another important observation, confirming a beneficial effect of immunotherapy, is a significant increase of $\mathrm{CD}^{+} / \mathrm{CD}^{+}+$ratio, since impaired, lowered $\mathrm{CD}^{+} / \mathrm{CD}^{+}$ratio is an immune defect typical for B-CLL. However, evaluating T cell function, we did not find any significant increase of in vitro $\mathrm{T}$ cell proliferation, stimulated by tumor antigens (lysates of autologous leukemic cells) after the end of therapy compared to the initial values. There was also no induction of specific CTLs during vaccinations. Many factors might be responsible for the lack of CTL induction in in vitro studies. First, despite activation, antigen presentation properties of CD40L-CLL cells might still be too weak to induce $\mathrm{T}$ cell proliferation. Another reason might be impaired function of $\mathrm{T}$ cells or the presence of cells in the cultures, that might suppress $\mathrm{T}$ cell proliferation. On the other hand, a notable finding was a significant improvement in the phagocytic abilities of DCs generated from peripheral blood monocytes obtained from patients with B-CLL after the end of immunotherapy. One might speculate that stimulation of DCs from the subcutis with antigens present in apoptotic bodies influences the immune response, and could to some extent restore the function of the cells participating in the anti-cancer response.

So far, few clinical trials on immunotherapies with autologous leukemic cells in B-CLL have been reported $(21,26,27)$, mostly with immune and rather transient clinical responses. As a possible reason for the lack of response, authors have claimed the impaired function of DCs and T cells, and increased level of $\mathrm{T}$ regulatory cells, CD $4^{+} / \mathrm{CD} 25^{+} / \mathrm{LAG}^{-} 3^{+} /$ FoxP $-3^{+}$, observed before and during treatment period. These results suggest that suppression of regulatory $\mathrm{T}$ cells might improve the results of cellular immunotherapy in B-CLL.

In conclusion, our results demonstrated the feasibility and safety of immunotherapy with autologous irradiated leukemic cells in patients with B-CLL. Vaccinations induced immune responses and we observed in some patients a decrease of the WBC count and a prolongation of the lymphocyte doubling time. These observations together with the rather simple procedure of vaccine preparation suggest that further investigation would be worthwhile. Since there was no clinical benefit of the use of BCG, one might consider the use of other adjuvants, such as CpG-rich oligonucleotides or incomplete Freund's adjuvant.

\section{References}

1. Kipps TJ: Chronic lymphocytic leukemia. Curr Opin Hematol 7: 223-234, 2000.

2. Dighiero G, Maloum K, Desablens B, et al: Chlorambucil in indolent chronic lymphocytic leukemia. French Cooperative Group on Chronic Lymphocytic Leukemia. N Engl J Med 338: 1506-1514, 1998.

3. Shanafelt TD and Call TG: Current approach to diagnosis and management of chronic lymphocytic leukemia. Mayo Clin Proc 79: 388-398, 2004.

4. Khorana A, Bunn P, McLaughlin P, Vose J, Stewart C and Czuczman MS: A phase II multicenter study of CAMPATH-1H antibody in previously treated patients with nonbulky nonHodgkin's lymphoma. Leuk Lymphoma 41: 77-87, 2001.

5. Schmidt SM, Schag K, Muller MR, et al: Survivin is a shared tumor-associated antigen expressed in a broad variety of malignancies and recognized by specific cytotoxic $\mathrm{T}$ cells. Blood 102: 571-576, 2003.

6. Mayr C, Bund D, Schlee M, Moosmann A, Kofler DM, Hallek M, and Wendtner CM: Fibromodulin as a novel tumor-associated antigen (TAA) in chronic lymphocytic leukemia (CLL), which allows expansion of specific CD8+ autologous T lymphocytes. Blood 105: 1566-1573, 2005.

7. Giannopoulos K, Li L, Bojarska-Junak A, et al: Expression of RHAMM/CD168 and other tumor-associated antigens in patients with B-cell chronic lymphocytic leukemia. Int J Oncol 29: 95-103, 2006.

8. Morales A, Eidinger D and Bruce AW: Intracavitary Bacillus Calmette-Guerin in the treatment of superficial bladder tumors. J Urol 116: 180-183, 1976.

9. Brandau S and Suttmann H: Thirty years of BCG immunotherapy for non-muscle invasive bladder cancer: a success story with room for improvement. Biomed Pharmacother 61: 299-305, 2007.

10. Vermorken JB, Claessen AM, van Tinteren $\mathrm{H}$, et al: Active specific immunotherapy for stage II and stage III human colon cancer: a randomised trial. Lancet 353: 345-350, 1999.

11. Hus I, Podhorecka M, Bojarska-Junak A, et al: The clinical significance of ZAP-70 and CD38 expression in B-cell chronic lymphocytic leukaemia. Ann Oncol 17: 683-690, 2006.

12. Bojarska-Junak A, Giannopoulos K, Kowal M, Dmoszynska A and Rolinski J: Comparison of methods for determining zetachain associated protein - 70 (ZAP-70) expression in patients with B-cell chronic lymphocytic leukemia (B-CLL). Cytometry B Clin Cytom 70: 293-301, 2006.

13. Crespo M, Bosch F and Villamor N: ZAP-70 expression as a surrogate for immunoglobulin-variable-region mutations in chronic lymphocytic leukaemia. N Engl J Med 348: 1764-1775, 2003.

14. Gricks CS, Zahrieh D, Zauls AJ, et al: Differential regulation of gene expression following CD40 activation of leukemic compared to healthy B cells. Blood 104: 4002-4009, 2004.

15. Giannopoulos K, Dmoszynska A, Rolinski J, Hus I and Schmitt M: The expression of survivin in patients with B-cell chronic lymphocytic leukemia (B-CLL). Acta Haemat Pol 36: 83-88, 2005.

16. McCune CS, O'Donnell RW, Marquis DM and Sahasrabudhe DM: Renal cell carcinoma treated by vaccines for active specific immunotherapy: correlation of survival with skin testing by autologous tumor cells. Cancer Immunol Immunother 32: 62-66, 1990.

17. Lotem M, Peretz T, Drize O, et al: Autologous cell vaccine as a post operative adjuvant treatment for high-risk melanoma patients (AJCC stages III and IV). The new American Joint Committee on Cancer. Br J Cancer 86: 1534-1539, 2002.

18. Hoover HC Jr, Brandhorst JS, Peters LC, et al: Adjuvant active specific immunotherapy for human colorectal cancer: 6.5-year median follow-up of a phase III prospectively randomized trial. J Clin Oncol 11: 390-399, 1993. 
19. Hanna MG Jr and Peters LC: Specific immunotherapy of established visceral micrometastases by BCG-tumor cell vaccine alone or as an adjunct to surgery. Cancer 42: 2613-2625, 1978.

20. Robinson MR: The experience with intravesical BCGimmunotherapy in the management of superficial bladder cancer in the United Kingdom. Prog Clin Biol Res 310: 147-151, 1989.

21. Wierda WG, Kipps TJ and Keating MJ: Novel immune-based treatment strategies for chronic lymphocytic leukemia. J Clin Oncol 23: 6325-6332, 2005.

22. Gitelson E, Hammond C, Mena J, Lorenzo M, Buckstein R, Berinstein NL, Imrie K and Spaner DE: Chronic lymphocytic leukemia-reactive $\mathrm{T}$ cells during disease progression and after autologous tumor cell vaccines. Clin Cancer Res 9: 1656-1665, 2003.

23. Ravandi F and O'Brien S: Immune defects in patients with chronic lymphocytic leukemia. Cancer Immunol Immunother 55: 197-209, 2006.
24. Kay NE, Hamblin TJ, Jelinek DF, et al: Chronic lymphocytic leukemia. Hematology 2002: 193-213, 2002.

25. Shimoni A, Marcus H, Canaan A, Ergas D, David M, Berrebi A and Reisner Y: A model for human B-chronic lymphocytic leukemia in human/mouse radiation chimera: evidence for tumor-mediated suppression of antibody production in lowstage disease. Blood 89: 2210-2218, 1997.

26. Spaner DE, Hammond C, Mena J, Foden C and Deabreu A: A phase $\mathrm{I} / \mathrm{II}$ trial of oxidized autologous tumor vaccines during the 'watch and wait' phase of chronic lymphocytic leukemia. Cancer Immunol Immunother 54: 635-646, 2005.

27. Biagi E, Rousseau R, Yvon E, et al: Responses to human CD40 ligand/human interleukin-2 autologous cell vaccine in patients with B-cell chronic lymphocytic leukemia. Clin Cancer Res 11: 6916-6923, 2005. 